\title{
HSPB7 GENE POLYMORPHISM ASSOCIATED WITH ANTHROPOMETRIC PARAMETERS OF OBESITY AND FAT INTAKE IN A CENTRAL EUROPEAN POPULATION
}

\author{
Tereza Pavlová1, ${ }^{2}$, Jan Novák ${ }^{1,3}$, Filip Zlámal ${ }^{1,2}$, Julie Bienertová-Vašků1, 2 \\ ${ }^{1}$ Department of Pathological Physiology, Faculty of Medicine, Masaryk University, Brno, Czech Republic \\ ${ }^{2}$ Research Centre for Toxic Compounds in the Environment, Faculty of Science, Masaryk University, Brno, Czech Republic \\ ${ }^{3}$ Department of Physiology, Faculty of Medicine, Masaryk University, Brno, Czech Republic
}

\begin{abstract}
SUMMARY
Objective: Heat shock proteins act as chaperones at the molecular level and therefore they have been investigated in numerous diseases associated with oxidative stress, including obesity. The aim of this study was to investigate the possible associations of genetic variability in the 3 '-untranslated region of the HSPB7 gene (rs1048261) with anthropometric and dietary parameters in a cohort of lean and obese Central European subjects.

Methods: A total of 708 Central European Caucasian individuals were enrolled in this study, 415 obese subjects and 293 non-obese subjects. The rs1048261 genotypes were established using a conventional PCR-based methodology.

Results: Significant differences were observed in the total daily fat intake between subjects with AT and TT genotypes $(82.6 \pm 29.2 \mathrm{~g}$ vs. $74.1 \pm 31.3$ $g, p=0.023)$ and also borderline significance in daily proportion of fat in the diet between AA and TT genotypes $(36.0 \pm 4.4 \%$ vs. $33.3 \pm 5.9 \%$, $p=0.061$. Based on the linear regression model we found association between rs 1048261 genotype and body fat percentage.

Conclusions: To the best of our knowledge, this is the first study which reports an association of defined genetic variability in the HSPB7 gene, rs1048261, with obesity and its associated anthropometric characteristics and dietary composition.
\end{abstract}

Key words: HSPB7, obesity, polymorphism, dietary composition, fat intake, rs1048261

Address for correspondence: T. Pavlová, Research Centre for Toxic Compounds in the Environment, Faculty of Science, Masaryk University, Kamenice 753/5, Building A29, 62500 Brno, Czech Republic. E-mail: pavlova@recetox.muni.cz

https://doi.org/10.21101/cejph.a4921

\section{INTRODUCTION}

Obesity is defined as an abnormal or excessive accumulation of fat tissue within the human body. The World Health Organization (WHO) defines obese individuals as persons with a body mass index (BMI) of $30 \mathrm{~kg} / \mathrm{m}^{2}$ or higher (1). An excessive accumulation of fat tissue leads to the activation of a chronic low-intensity inflammatory response which further impairs extracellular and intracellular signaling pathways and promotes the development of obesity comorbidities such as diabetes mellitus (2) or other inflammation-related diseases such as cardiovascular diseases (3) or cancer (4). The higher prevalence of such diseases, which constitute leading causes of death in the developed world (5), also to some extent explains the increase in overall and specifically in cardiovascular mortality in obese subjects. Since the number of obese individuals is increasing and has doubled between 1980 and 2008 (from $5 \% / 8 \%$ to $10 \% / 14 \%$ in men/women) (6), a better understanding of the genetic aspects affecting the development and course of obesity is reasonable.

Oxidative stress is caused by the presence of an excessive amount of reactive oxygen species (ROS) in cells (7). The presence of ROS leads to cell damage and consequently to the emergence of serious diseases, e.g. atherosclerosis (8), diabetes mellitus (9), cancer (10), and cardiovascular diseases (11). In humans, fat accumulation positively correlates with oxidative stress (12). The elevation of free fatty acids in obesity leads to increased nicotinamide adenine dinucleotide phosphate oxidase (NADPH oxidase) activity (13) and an increase in ROS production. This results in the elevation of oxidative stress in obese individuals. Furthermore, oxidative stress leads to the dysregulated production of adipocytokines in accumulated fat, which contributes to the development of obesity-associated metabolic syndrome.

Heat shock proteins (HSPs) constitute a highly conserved polypeptide family found in all living organisms. While some HSPs are expressed constitutively within cells, thus functioning as molecular chaperones (14), the expression of other HSPs is induced by a variety of stress agents, e.g. heat stress, oxidative stress, the presence of heavy metal ions, etc.; as a result, these HSPs are thereby involved in inflammatory response $(14,15)$. According to their molecular weight, HPSs are categorized as belonging to several groups: HSP110 (HSPH), HSP90 (HSPC), HSP70 (HSPA), HSP40 (DNAJ), small HSP (HSPB) (16). This study is focused on HSPB7, a member of the small HSPs family.

HSPB7 was identified in 1999 (17) and, like all other small HSPs (18), is characterized by an evolutionary conserved $\alpha$-crystallin-domain. It is also known as a cardiovascular HSP 
(cvHSP) due to its predominant expression in the human heart (17). However, its increased expression was also observed in the skeletal muscle and brown adipose tissue of Zucker fatty rats (17), in the skeletal muscle of leptin-deficient mice (19) and, interestingly, also in the subcutaneous abdominal adipose tissue of obese subjects (20). This may be explained by the fact that HSPs are involved in inflammatory response (21) and thus also in the state of low-grade inflammation - obesity.

The expression of HSPB7 may be regulated by various factors. One of them is the binding of micro-RNAs (miRNA) to the 3 'untranslated region (UTR) of the gene, which may affect HSPB7 expression and thereby also the course of a disease associated with the gene. The variability of the UTR affects the binding of miRNAs to this region. One of the variations in the HSPB7 UTR is rs 1048261, with ancestral allele T substituted by an A. This study thus aims to investigate whether genetic variability in the 3 '-UTR of the HSPB7 gene, specifically rs1048261, affects anthropometric as well as dietary parameters in a cohort of lean and obese subjects of Central European origin.

\section{MATERIALS AND METHODS}

\section{Subjects}

A total of 708 unrelated Czech Caucasian individuals were recruited for this study in a mass media campaign addressing the general population of the South Moravian Region of the Czech Republic (22). Participants were divided into obese and non-obese groups according to BMI. The inclusion and exclusion criteria were derived from a study conducted by Ma et al. (23). The current study was conducted according to guidelines set up in the Declaration of Helsinki and all procedures involving human subjects were approved by the Committee for Ethics of Medical Experiments on Human Subjects, Faculty of Medicine, Masaryk University, Brno, Czech Republic. Written informed consent was obtained from all subjects prior to all performed measurements and archived.

\section{Anthropometry Measurements}

The obese group included 415 subjects (BMI $\geq 30 \mathrm{~kg} / \mathrm{m}^{2}$, mean BMI $36.6 \pm 5.7 \mathrm{~kg} / \mathrm{m}^{2}$, mean age $51.5 \pm 12.2$ years) and the control (non-obese) group included 293 normal-weight subjects (20 $\mathrm{kg} / \mathrm{m}^{2}<\mathrm{BMI}<30 \mathrm{~kg} / \mathrm{m}^{2}$, mean BMI $25.5 \pm 3.0 \mathrm{~kg} / \mathrm{m}^{2}$, mean age $43.2 \pm 15.0$ years) with no history of childhood obesity or eating disorders. Additional phenotypic measurements included weight, height, systolic and diastolic blood pressure, skinfold thickness, body fat, body water, waist and hip circumference and waist-hip ratio (WHR). Body composition was assessed by means of bioelectrical impedance analysis using a single frequency bioimpedance analyser (BodyStat Ltd, Douglas, Isle of Man, UK) with the subject lying in a supine position. Height was measured using a calibrated stadiometer and weight (in light indoor clothes and without shoes) was measured using a precisely calibrated set of scales.

\section{Nutritional Assessment}

Participants were advised to complete standardized 7-day food records. Food intake data were obtained from study sub- jects and further analyzed. The percentage of daily energy intake from carbohydrates, fat and protein as well as total energy and macronutrient intake were calculated using the Nutrimaster Diet Analysis software modified for the Czech population (Abbott Laboratories, Abbott Park, IL, USA).

\section{Genotyping}

Analyzed DNA was extracted from $5 \mathrm{ml}$ of the patients' saliva after 3 hours of fasting using a standard extraction protocol involving proteinase K. Genotyping of the rs1048261 was performed using a standard polymerase chain reaction followed by restriction fragment length polymorphism (PCR-RFLP) The amplified 219 bp fragment was generated using the following primers: forward 5'-GTGCTGTGCTTTGTCACTGA-3' and reverse 5'-CCAGGGTTAAGGCTGATGGA-3'. PCR was performed as follows, denaturation process for $10 \mathrm{~min}$ at $95^{\circ} \mathrm{C}$; 32 cycles of denaturation for $30 \mathrm{~s}$ at $95^{\circ} \mathrm{C}$, annealing for $20 \mathrm{~s}$ at $60^{\circ} \mathrm{C}$ and extension for $30 \mathrm{~s}$ at $72^{\circ} \mathrm{C}$; and final extension step for $5 \mathrm{~min}$ at $72^{\circ} \mathrm{C}$, followed by a cooling process to $15^{\circ} \mathrm{C}$. The PCR product was then digested using 3 units of the restriction enzyme PvuII. The fragments were visualized using electrophoresis on $4 \%$ agarose gel with ethidium bromide staining and visualization using UV illumination and an Image Analyzer (AlphaImagere 1220; Alpha Innotech Corp., San Leandro, CA, USA). O'RangeRuler ${ }^{\mathrm{TM}} 50 \mathrm{bp}$ DNA Ladder was used for fragment sizing. To assess genotyping reliability, double sampling was performed in more than $20 \%$ of all samples; no differences were observed. Quality and negative controls were always used to identify possible false positive cases. Alleles are reported in forward orientation to the genome.

\section{Statistics}

Data normality was tested using Shapiro-Wilk test, Pearson's test and Kolmogorov-Smirnov test as well as graphically (i.e. using histograms and quantile-quantile plots). In case of skewed variables, data was log-transformed or square root transformed and normality was subsequently re-analyzed.

After normality testing, the appropriate method for intergroup comparisons was selected. For the purpose of intergroup comparisons, the patients were categorized according to sex (men, women), genotype (AA, AT, TT) and obesity status (obese, nonobese). These categorical data, characterized by the distribution of allele and genotype frequencies in the HSPB7 gene, were organized in a three-way contingency table. The independence of these variables was tested using a log-linear model and the Cochran-Mantel-Haenszel test. Finally, an analysis of variance (ANOVA), t-test, Kruskal-Wallis test, Mann-Whitney test, Kolmogorov-Smirnov test and linear regression model were used to analyze differences between the groups. The significant differences detected using ANOVA were corrected using Tukey's honestly significant difference post hoc test.

Backward stepwise regression was selected for linear model construction (i.e. the initial model included all potential confounding variables such as gender, age, obesity status, HSPB7). Once the initial model was constructed, the number of variables was subsequently reduced so that the final model complied with the initial one; this approach was based on the Akaike information 
criterion (AIC). All models were properly adjusted for all potential confounding variables.

A correlation analysis was performed using a matrix diagram and the Pearson's correlation coefficient. For descriptive purposes, mean values are presented using untransformed values. Results are expressed as mean \pm standard deviation (SD) unless otherwise stated. Data analysis was performed using the R-program package. Consensual values of $\mathrm{p}<0.05$ were considered statistically significant.

\section{RESULTS}

Basic anthropometric and dietary data are presented in Table 1 using the mean and SD as description variables. The compliance of genotype distributions of HSPB7 with the Hardy-Weinberg equilibrium (HWE) was tested using the asymptotic Pearson's $\mathrm{chi}^{2}$ test $(\mathrm{p}=0.078)$, with genotype distribution in agreement with HWE. Genotypes in the cohort were presented as follows, 333 (47\%) TT, 290 (41\%) AT and 85 (12\%) AA. The frequency of A allele is 0.325 , which is in accordance with European part of 1000 Genomes project ( $\mathrm{A}=0.322 ; 1,006$ participants). No significant differences were found in genotype distribution between genders or between lean and obese subjects.

The results of the intergroup comparison based on linear modelling of the relationship between HSPB7 and the anthropometric and nutritional variables are summarized in Table 2 (non-significant interactions were omitted).

\section{Analysis of Sex-dependent Association of HSPB7 with Obesity}

Using the log-linear model as well as the Cochran-MantelHaenszel test, no statistically significant association of the HSPB7 genotype and/or allele distribution with gender and obesity status was observed $\left(\chi^{2}=0.036, p=0.959\right)$.

\section{HSPB7 Polymorphism Association with Anthropo- metric Parameters}

We tested whether the various genotypes of the HSPB7 gene affect any of investigated anthropometric characteristics with regard to the obesity status and sex of the individuals. We observed associations of investigated polymorphism with triceptal skinfold thickness and biceptal skinfold thickness in males for AA vs. TT and AT vs. TT (22.8 $\pm 7.7 \mathrm{~mm}$ vs. $18.1 \pm 6.0 \mathrm{~mm}$ and $17.3 \pm 8.3 \mathrm{~mm}$ vs. $14.0 \pm 7.4 \mathrm{~mm}, \mathrm{p}=0.051$ and 0.038 , respectively) (Table 2 ).

\section{Analysis of HSPB7 and Percentage of Body Fat and WHR}

A linear regression model was constructed for the variables body fat and WHR, all models were basically adjusted for age, gender and BMI and the variables were consecutively reduced using the backward stepwise regression procedure. We found no association between WHR and rs1048261 genotypes. On the other hand, based on this model we found association between rs1048261 genotypes and percentage of body fat in this cohort. Specifically, the individuals with AA genotype are associated with higher percentage of body fat compared to $\mathrm{T}$ allele carriers.

\section{HSPB7 and Dietary Composition}

We tested potential associations of the HSPB7 polymorphism with total daily energy intake, absolute intake of macronutrients (proteins, carbohydrates and fats), proportion of macronutrients in total daily energy intake and intake of fiber, liquids, cholesterol and vitamin C. In the entire group of obese subjects (i.e. pooled males and females), the borderline significance was identified in the daily proportion of fat in the diet between AA and TT (36.0 $\pm 4.4 \%$ vs. $33.3 \pm 5.9 \%, p=0.061)$. Similarly, the borderline significance and significant differences were observed in the average total daily fat intake, regardless of sex or obesity between AA and TT $(80.5 \pm 29.8 \mathrm{~g}$ vs. $74.1 \pm 31.3 \mathrm{~g}, \mathrm{p}=0.082)$ and also between AT and TT $(82.6 \pm 29.2 \mathrm{~g}$ vs. $74.1 \pm 31.3 \mathrm{~g}, \mathrm{p}=0.023)$. In addition, rank moderate correlation was confirmed between cholesterol intake, fat intake and proportion of fat in the diet. No association with the total daily energy intake, cholesterol intake, fiber intake, and vitamin $\mathrm{C}$ intake was observed.

\section{DISCUSSION}

Investigating genes implicated in obesity is crucial for understanding the pathogenesis of this complex multifactorial disease. The continuous rise in the incidence of obesity in recent years calls for the clarification of distinct molecular mechanisms and genetic causes, including the identification of pathological alleles (24). An improved understanding could form a strong basis for targeted prophylaxis in patients at risk of obesity development and could also lead to the development of individual, highly targeted therapy.

A cellular response to oxidative stress is basically represented by the upregulation of HSPs (25). The HSP-based cellular response to stress generally includes molecular sensing of stress along with protein sorting, quality control, degradation or refolding of proteins and also the inhibition of inflammation, apoptosis and protein misfolding, all acting together to support cell survival (25). No robust data describing the dynamics of HSPB7 levels in oxidative stress are currently available and only a limited amount of information is available with respect to the association of HSPB7 and obesity. A positive correlation between obesity and HSPB7 expression was reported in 2013 in a study by GonzálesMuniesa et al. who detected a higher expression of HSPB7 in subcutaneous abdominal adipose tissue from obese male subjects compared to lean male subjects (20).

More information on HSPB7 expression is available from cardiovascular diseases - it has been reported that elevated concentrations of HSPB7 are produced in the plasma of patients with acute coronary syndrome (26). This increase is being explained mainly by the rapid release of HSPB7 from cardiomyocytes into the circulation after myocardial necrosis. Moreover, various polymorphisms in the HSPB7 gene have been associated with the pathogenesis of other cardiovascular diseases, e.g. idiopathic dilated cardiomyopathy (27), sporadic (28) and advanced heart failure (29).

The investigated polymorphism rs 1048261 is located in the 3'-UTR of the HSPB7 gene and the sequences in 3'-UTR that surround this polymorphism are supposed to be targeted by miR- 


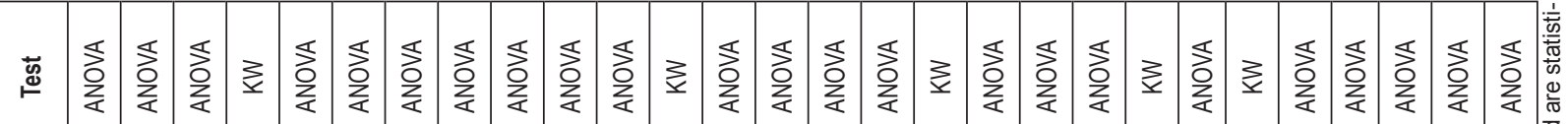

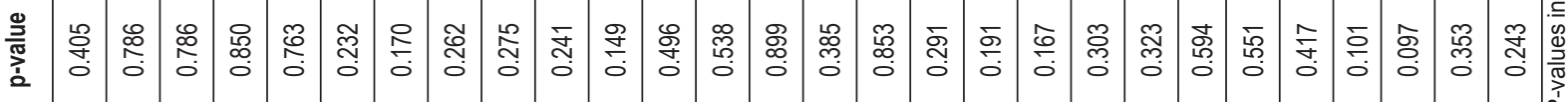

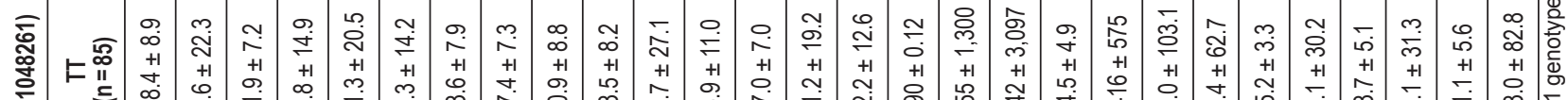

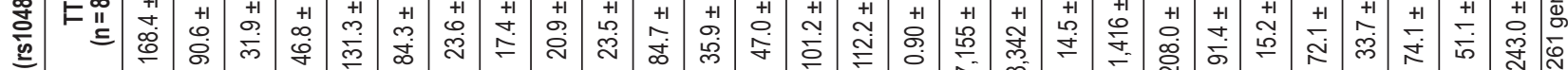
商

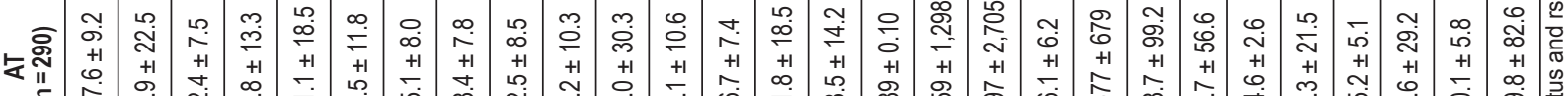

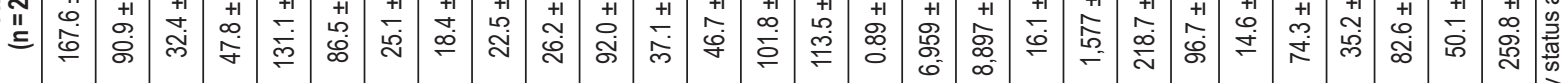

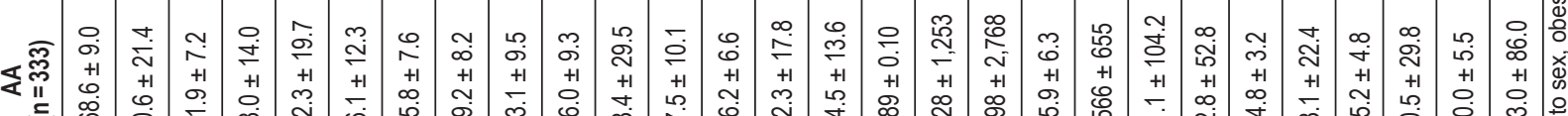

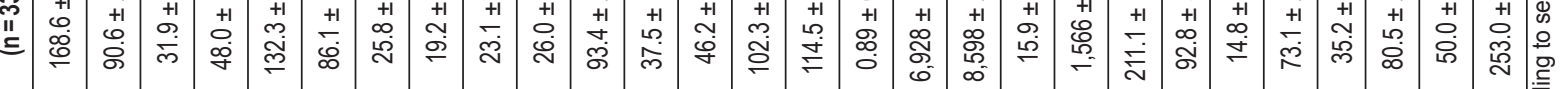

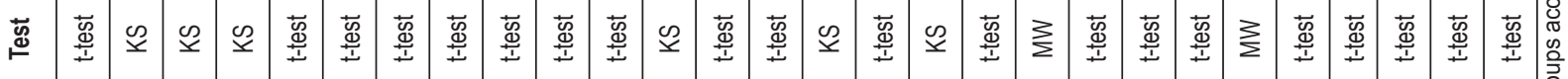

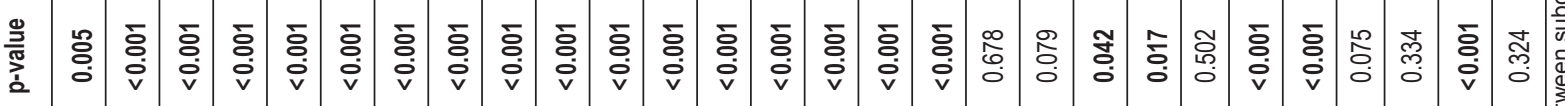

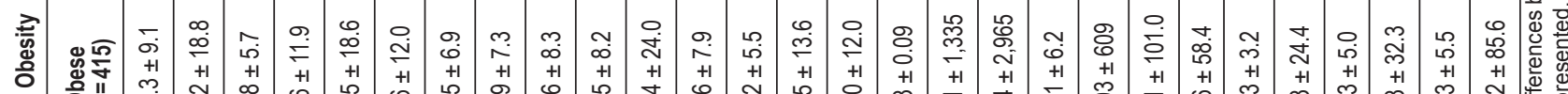

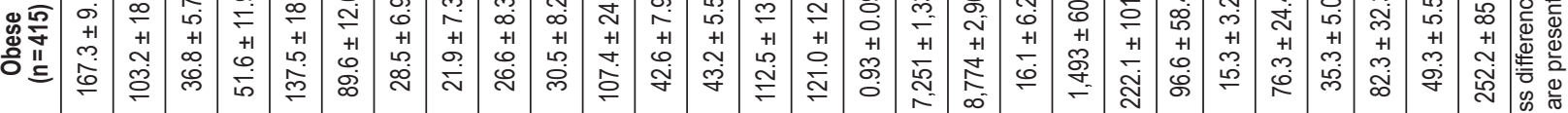

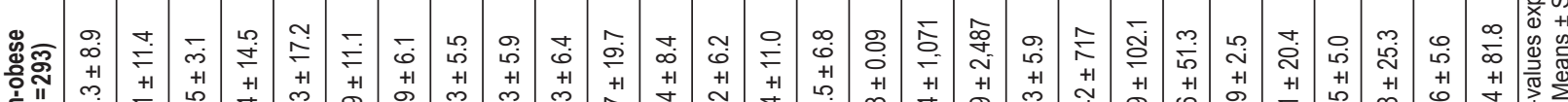

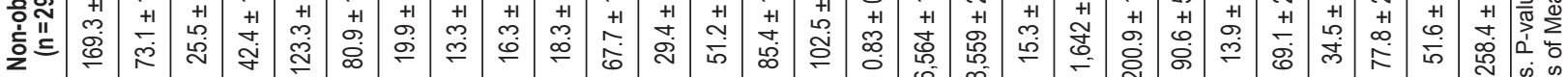

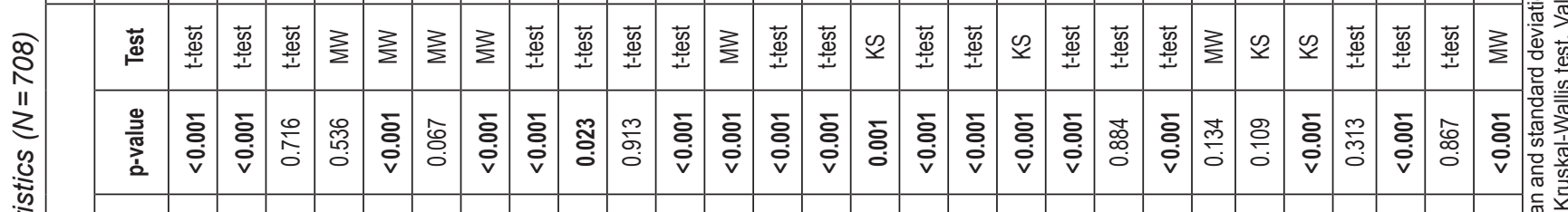

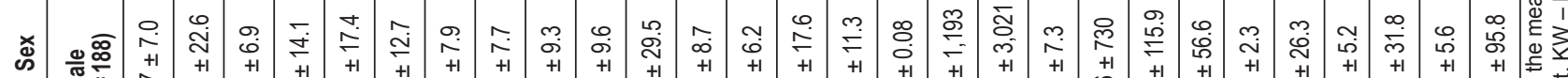

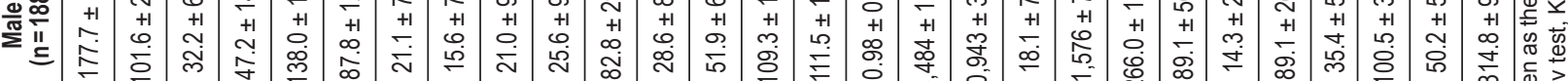

$\div$

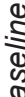

o

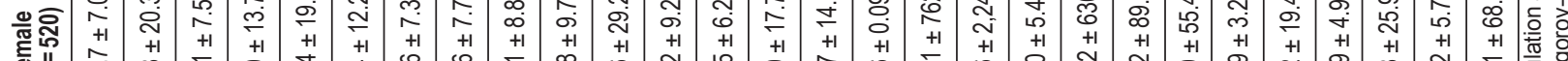

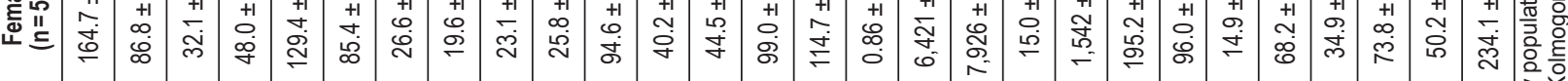

枍

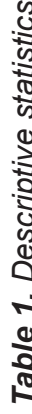

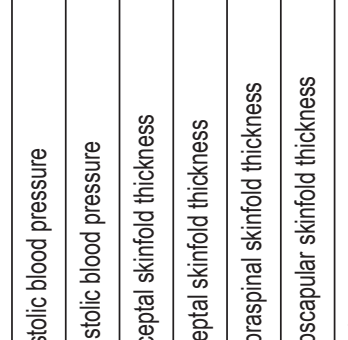

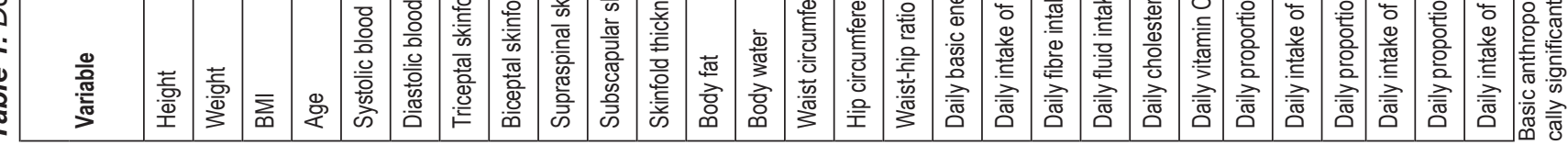

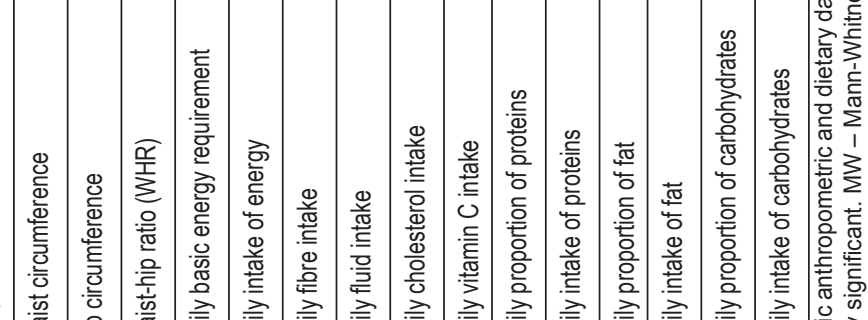


Table 2. Association between HSPB7 Genotypes and anthropometric and nutritional variables

\begin{tabular}{|c|c|c|c|c|c|c|}
\hline Variable & Statistically significant differences & $\begin{array}{c}\text { Males } \\
\mathrm{n}\end{array}$ & $\begin{array}{c}\text { Females } \\
\mathrm{n}\end{array}$ & $\begin{array}{c}\text { Males } \\
\text { Mean } \pm \text { SD }\end{array}$ & $\begin{array}{c}\text { Females } \\
\text { Mean } \pm \text { SD }\end{array}$ & p-value \\
\hline Daily proportion of fat in the diet & Obese males + females: AA vs. TT & 81 & 26 & $36.0 \pm 4.4 \%$ & $33.3 \pm 5.9 \%$ & 0.061 \\
\hline \multirow{2}{*}{ Total daily intake of fat } & Non-obese + obese males + females: AA vs. TT & 246 & 59 & $80.5 \pm 29.8 \mathrm{~g}$ & $74.1 \pm 31.3 \mathrm{~g}$ & 0.082 \\
\hline & Non-obese + obese males + females: AT vs. TT & 205 & 59 & $82.6 \pm 29.2 \mathrm{~g}$ & $74.1 \pm 31.3 \mathrm{~g}$ & 0.023 \\
\hline Triceptal skinfold thickness & Males: AA vs. TT & 49 & 18 & $22.8 \pm 7.7 \mathrm{~mm}$ & $18.1 \pm 6.0 \mathrm{~mm}$ & 0.051 \\
\hline Biceptal skinfold thickness & Males: AA vs. AT & 49 & 49 & $17.3 \pm 8.3 \mathrm{~mm}$ & $14.0 \pm 7.4 \mathrm{~mm}$ & 0.038 \\
\hline
\end{tabular}

between groups were tested using ANOVA and then $p$-values were corrected using Tukey's honestly significant difference post hoc test.

874 and miR-143 (based on miRdSNP*, accessed November 27, 2015), previously functionally validated. miR-874 is generally involved in cell cycle regulation, apoptosis and proliferation and it has been reported recently that its expression is temperaturesensitive (30). Importantly, miR-874 is also implicated in the regulation circuits of another HSP, HSPB70, whereas miR-874 dramatically increases the gene expression under the conditions of moderate stretch injury (30). In another study, miR-874 expression was linked to the development of obesity (31).

As for the miR-143, it has been previously demonstrated that miRNA-143 is upregulated during pre-adipocyte 3T3-L1 differentiation in a cultured primary human adipocyte model system, thus suggesting an important role of this miRNA in human adipose tissue (32). Moreover, the authors suggest that inhibition of miR143 effectively inhibits adipocyte differentiation. Therefore, both of these miRNAs represent biologically plausible factors linking HSPs expression with obesity.

The mechanism by which aberrant expression of HSPB7 gene may influence accumulation of body fat, consecutively leading to obesity, is currently unknown. Interestingly, HSPB7 has not been linked to obesity except for the study by Gonzáles-Muniesa et al. (33) but there are several studies reporting its association to cardiovascular disease; common variants in this gene being associated with systolic heart failure (34). Wang et al. suggest that miR-874 may act via a regulatory pathway involving FoxO3a and caspase-8 (35), whereas the introduction of FoxO3a-siRNA into 3T3-L1 cells in experiment suppressed the oxidative stressinduced expression of Bim mRNA, as well as the glucose oxidase-induced apoptosis. This could indicate the ROS-induced apoptosis in undifferentiated 3T3-L1 cells via the expression of FoxO3a, whereas FoxO expression suppressed the ROS-induced apoptosis in differentiated 3T3-L1 cells via the expression of ROS-scavenging enzymes. It can be therefore hypothesized that the effect of the rs 1048261 polymorphism on body weight could be mediated via the following cascade: rs 1048261 (alteration of proximity of miR-874 and/or miR-143 binding site) - aberrant binding of miR-874 and/or miR-143 - altered levels of HSPB7 - aberrant signalling via FoxO3a - aberrant proliferation of adipocytes - accumulation of fat-obesity.

The biggest strength of this study is the investigation of the chosen polymorphism in a relatively large sample $(n=807)$ of highly homogenous Caucasian population of South Moravia, Czech Republic. However, the major limitation of this study is the absence of data on functional consequences of this polymorphism. Therefore, a functional study is needed to fill this gap. The uneven gender distribution across the cohort may also be a limitation, although the sex was properly adjusted. Moreover, it is also possible that more potential confounding factors could have been considered.

\section{CONCLUSIONS}

Based on our results, the A allele of the rs1048261 in the 3'UTR of the HSPB7 gene is associated with a higher intake of fat in the diet in general (obese and non-obese population), higher proportion of fat in the diet of obese subjects, or increased body fat percentage in the whole tested population. This is well in accordance with previous findings regarding the higher expression of HSPB7 in obese subjects $(17,19,20)$. However, the mechanistic link between HSPB7 expression and genetic variability in its 3'-UTR has yet to be experimentally validated. In conclusion, to the best of our knowledge, this is the first population study to report an association of defined genetic variability in the HSPB7 gene with obesity and its associated anthropometric characteristics and dietary composition. In this study, we observed significant and consistent association between a distinct genetic trait (HSPB7 gene variability) and a higher proportion of fat in the diet.

\section{Acknowledgement}

This study was carried out in part thanks to funds provided by the RECETOX research infrastructure (the Ministry of Education, Youth and Sports - MEYS, LM2015051), CETOCOEN PLUS (MEYS, CZ.02.1.0 1/0.0/0.0/15_003/0000469).

\section{Conflict of Interests}

None declared

\section{Adherence to Ethical Standards}

Signed informed consent was obtained from all participants and archived. The study was approved by the Committee for Ethics of Medical Experiments on Human Subjects, Faculty of Medicine, Masaryk University (Brno, Czech Republic) in adherence to the Declaration of Helsinki guidelines. 


\section{REFERENCES}

1. World Health Organization. Obesity [Internet]. Geneva: WHO [cited 2014 Aug 1]. Available from: http://www.who.int/topics/obesity/en/.

2. Gregor MF, Hotamisligil GS. Inflammatory mechanisms in obesity. Annu Rev Immunol. 2011;29:415-45.

3. Poirier P, Eckel RH. Obesity and cardiovascular disease. Curr Atheroscler Rep. 2002 Nov;4(6):448-53.

4. Calle EE, Thun MJ. Obesity and cancer. Oncogene. 2004;23(38):6365-78

5. World Health Organization. The top 10 causes of death [Internet]. Geneva: WHO [cited 2014 Dec 3]. Available from: http://www.who.int/ mediacentre/factsheets/fs310/en/.

6. World Health Organization. Obesity and overweight [Internet]. Geneva: WHO [cited 2014 Aug 1]. Available from: http://www.who.int/mediacentre/factsheets/fs311/en/.

7. Betteridge DJ. What is oxidative stress? Metabolism. 2000 Feb;49(2 Suppl 1):3-8.

8. Singh U, Jialal I. Oxidative stress and atherosclerosis. Pathophysiology. 2006 Aug;13(3):129-42.

9. Yang H, Jin X, Kei Lam CW, Yan S-K. Oxidative stress and diabetes mellitus. Clin Chem Lab Med. 2011 Nov;49(11):1773-82.

10. Reuter S, Gupta SC, Chaturvedi MM, Aggarwal BB. Oxidative stress, inflammation, and cancer: how are they linked? Free Radic Biol Med. 2010 Dec 1;49(11):1603-16.

11. Dhalla NS, Temsah RM, Netticadan T. Role of oxidative stress in cardiovascular diseases. J Hypertens. 2000 Jun;18(6):655-73.

12. Furukawa S, Fujita T, Shimabukuro M, Iwaki M, Yamada Y, Nakajima $\mathrm{Y}$, et al. Increased oxidative stress in obesity and its impact on metabolic syndrome. J Clin Invest. 2004 Dec 15;114(12):1752-61.

13. Inoguchi T, Li P, Umeda F, Yu HY, Kakimoto M, Imamura M, et al. High glucose level and free fatty acid stimulate reactive oxygen species production through protein kinase $\mathrm{C}$-dependent activation of $\mathrm{NAD}(\mathrm{P}) \mathrm{H}$ oxidase in cultured vascular cells. Diabetes. 2000 Nov;49(11):1939-45.

14. De Maio A. Heat shock proteins: facts, thoughts, and dreams. Shock Augusta Ga. 1999 Jan;11(1):1-12

15. Schlesinger MJ. Heat shock proteins. J Biol Chem. 1990 Jul 25;265(21):12111-4.

16. Kampinga HH, Hageman J, Vos MJ, Kubota H, Tanguay RM, Bruford EA, et al. Guidelines for the nomenclature of the human heat shock proteins. Cell Stress Chaperones. 2009 Jan;14(1):105-11.

17. Krief S, Faivre JF, Robert $P$, Le Douarin B, Brument-Larignon N, Lefrère I, et al. Identification and characterization of cvHsp. A novel human small stress protein selectively expressed in cardiovascular and insulin-sensitive tissues. J Biol Chem. 1999 Dec 17;274(51):36592-600.

18. Caspers GJ, Leunissen JA, de Jong WW. The expanding small heat-shock protein family, and structure predictions of the conserved "alpha-crystallin domain". J Mol Evol. 1995 Mar;40(3):238-48.

19. Sáinz N, Rodríguez A, Catalán V, Becerril S, Ramírez B, Gómez-Ambrosi $\mathrm{J}$, et al. Leptin administration downregulates the increased expression levels of genes related to oxidative stress and inflammation in the skeletal muscle of ob/ob mice. Mediators Inflamm. 2010 Jun 30;2010:e784343. doi: 10.1155/2010/784343.

20. González-Muniesa P, Marrades MP, Martínez JA, Moreno-Aliaga MJ. Differential proinflammatory and oxidative stress response and vulnerability to metabolic syndrome in habitual high-fat young male consumers putatively predisposed by their genetic background. Int J Mol Sci. 2013 Aug 22;14(9):17238-55.

21. Moseley PL. Heat shock proteins and the inflammatory response. Ann N Y Acad Sci. 1998 Sep 29;856:206-13.

22. Bienertová Vašků $J$, Bienert $P$, Tomandl $J$, Forejt M, Vavřina $M$, Kudělková J, et al. No association of defined variability in leptin, leptin receptor, adiponectin, proopiomelanocortin and ghrelin gene with food preferences in the Czech population. Nutr Neurosci. 2008;11(1):2-8.

23. Ma Y, Bertone ER, Stanek EJ, Reed GW, Hebert JR, Cohen NL, et al. Association between eating patterns and obesity in a free-living US adult population. Am J Epidemiol. 2003 Jul 1;158(1):85-92.

24. Clément K, Ferré P. Genetics and the pathophysiology of obesity. Pediatr Res. 2003 May;53(5):721-5.

25. Kalmar B, Greensmith L. Induction of heat shock proteins for protection against oxidative stress. Adv Drug Deliv Rev. 2009 Apr 28;61(4):310-8.

26. Chiu TF, Li CH, Chen CC, Chen CH, Cheng CJ, Yan YT, et al. Association of plasma concentration of small heat shock protein B7 with acute coronary syndrome. Circ J Off J Jpn Circ Soc. 2012;76(9):2226-33.

27. Stark K, Esslinger UB, Reinhard W, Petrov G, Winkler T, Komajda M, et al. Genetic association study identifies HSPB7 as a risk gene for idiopathic dilated cardiomyopathy. PLoS Genet. 2010 Oct 21;6(10):e1001167. doi: 10.1371/journal.pgen.1001167.

28. Matkovich SJ, Van Booven DJ, Hindes A, Kang MY, Druley TE, Vallania FLM, et al. Cardiac signaling genes exhibit unexpected sequence diversity in sporadic cardiomyopathy, revealing HSPB7 polymorphisms associated with disease. J Clin Invest. 2010 Jan;120(1):280-9.

29. Cappola TP, Li M, He J, Ky B, Gilmore J, Qu L, et al. Common variants in HSPB7 and FRMD4B associated with advanced heart failure. Circ Cardiovasc Genet. 2010 Apr;3(2):147-54

30. Truettner JS, Motti D, Dietrich WD. MicroRNA overexpression increases cortical neuronal vulnerability to injury. Brain Res. 2013 Oct 2;1533:12230 .

31. Milagro FI, Miranda J, Portillo MP, Fernandez-Quintela A, Campión J, Martínez JA. High-throughput sequencing of microRNAs in periphera blood mononuclear cells: identification of potential weight loss biomarkers. PloS One. 2013;8(1):e54319. doi: 10.1371/journal.pone.0054319.

32. Esau C, Kang X, Peralta E, Hanson E, Marcusson EG, Ravichandran LV, et al. MicroRNA-143 regulates adipocyte differentiation. J Biol Chem. 2004 Dec 10;279(50):52361-5

33. González-Muniesa P, Marrades MP, Martínez JA, Moreno-Aliaga MJ. Differential proinflammatory and oxidative stress response and vulnerability to metabolic syndrome in habitual high-fat young male consumers putatively predisposed by their genetic background. Int J Mol Sci. 2013 Aug 22;14(9):17238-55.

34. Garnier S, Hengstenberg C, Lamblin N, Dubourg O, De Groote P, Fauchier $\mathrm{L}$, et al. Involvement of BAG3 and HSPB7 loci in various etiologies of systolic heart failure: Results of a European collaboration assembling more than 2000 patients. Int J Cardiol. 2015 Jun 15;189:105-7.

35. Wang K, Liu F, Zhou L-Y, Ding S-L, Long B, Liu C-Y, et al. miR-874 regulates myocardial necrosis by targeting caspase- 8 . Cell Death Dis. 2013;4(7):e709. doi: 10.1038/cddis.2013.233.

Received September 6, 2016 Accepted in revised form November 20, 2018 